\title{
The Thinking of Disposition Optimization of Naval Surface Vessel
}

\author{
Shan Hongyan, Ma Liang and Tian Feng \\ Department of Surface Ship Command, Dalian Naval Academy, Dalian, 116018,China \\ 446982051@qq.com
}

\section{Keywords: Surface vessel; Disposition; Optimization}

\begin{abstract}
Under the condition of information, current disposition of naval warship cannot satisfy the operation and training, optimizing is necessary. Analyzing the problems of current disposition, relying on the prospective target, methods and process is put forward. It provides references for the disposition optimizing of naval warships.

Ship deployment is the arrangement of the position and responsibility of the ship's personnel on the ship. It is the basic basis for the ship organization's combat readiness, completing the training mission and carrying out the daily work, which is also the fundamental guarantee to improve the training level and play its combat effectiveness. With constant expansion of naval ship mission, focus on a more comprehensive way of dealing with threats, more safely, to complete the task, more fully application equipment, and to organize a finer crews, ships deployment needs to set up and optimized.
\end{abstract}

\section{Main Problems Existing in the Existing Ship Deployment}

Ship current deployment include operational deployment and daily deployment, including operational deployment including attack, coordination, protection, aircraft operation, such as deployment, daily class deployment, navigation control, such as deployment, mainly including daily work just training style was one of those based on the total for the top and combat readiness deployment under the condition of training ${ }^{[2]}$, from combat style see lack of all kind of deployment and combat, constant vigilance, threats, disposal and effective recovery ability is not strong. The specific performance is as follows:

Lack of Overall Planning. Current deployment is primarily a combat action for deployment, no specific action responsibility, all the protection, attack and co-ordinated action, is a task corresponds to a deployed combat class deployed at all levels should be over which combat operations, fight the level to which class deployed what integrated combat ability and battle damage control ability, positioning is not clear enough, the lack of overall plan as a whole, comprehensive ability is not enough.

The Command Efficiency is not High. Current deployment is due to the single individual action and less considering the relations among various operational deployment, between command posts, operations, command, coordination randomly, command concentration; Specific to operational action, there are also problems of operational command and command coordination, which influence and restrict operational effectiveness.

Conflict of Duty. The crews and responsibilities defined by the deployment of a variety of combat operations conflict happens from time to tome, at the same time of outside air (sea) feeling threat, internal damage control hazards, points more on duty to perform tasks at the same time, will not be able to take into account the threat, disposal, it is difficult to deal with a variety of threats and accomplish a variety of tasks at the same time.

Insufficient Continuous Operation. It is an important index to continue to deal with threats and maintain combat capability. Current deployment under the combat deployment, personnel, equipments were not clear, crews need what ability, need not to need a mastering many skills while specializing in one or more dedicated pluripotent crews supplements such as unclear, not for full-time d alerts and defense were on duty, no continuous operations organization support to meet the sea. 
Fine Management is not Enough. The current deployment of personal responsibility is too principled to fully adapt to people's responsibilities and specific management requirements; Which crews are a response to other tasks at the same time can be adjusted and threat, which crews should have the qualification for mastering many skills while specializing in one, the current deployment is not clearly, personnel management is too general, to a certain extent has also led to a variety of threat at the same time the fuss.

\section{The Ship Deployment Sets the Guiding Ideology and the Optimization Adjustment Goal Principle}

Optimizes the current deployment, and make it close to combat training needs under the condition of informatization, first of all, in order to establish the guiding ideology of deployment Settings and optimizing and adjusting the objectives and principles, a clear "target of traction, the principle of" the basic direction.

Guiding Ideology of Ship Deployment Setting. Ships deployment Settings should be able to fight and win victories as fundamental follow, perfect the shipborne combat command system, optimize operation command process, as a whole operation coordination, refined, personnel responsibilities, ships with effective ability to cope with various threats and accomplish a diverse array of tasks.

The Target of Optimization and Adjustment of Ship Deployment. Ship target deployment optimization and adjustment can be summarized as "clear positioning, strong responsibility, were reasonable and capability integration", implement the jackboots clear which fighting positions in coordination with who, who is responsible for, what, what kind of equipment, complete tasks, to achieve any goal.

Is a clear positioning, to combat deployment is divided into several levels, as the main form of combat class deployment, and over the host, standard, compatible with all operations, make optimization after the deployment of the adjustment "as a whole is compatible with combat deployment". The second is to make the responsibility clear, accurate definition crews responsibility, most combat under the optimal grouping and adjustable, specification deployed at all levels under the jackboots concerted action and service requirements, make optimization adjusted deployment "clear management responsibility deployment". Three is were reasonable, to a reasonable specification on duty personnel, equipments were divided, and transfer requirements, keep ships to full-time multi-dimensional regulation level of deployment and combat, make optimization adjusted deployment "continuing operations were deployed"; Four is the ability to integrate to the current "deployment" into "function deployment", a combat class deployment to be deployed at the corresponding level mission need various ability, make optimization adjusted deployment "based on the ability of function deployment".

Principle of Optimization and Adjustment of Ship Deployment. Ships deployment optimization adjustment can be summarized as the principle of "integration compatibility, ability to plan as a whole, intensive and efficient, fine linkage", reflects the combat class deployed at all levels should have what ability, how to give full play to the ability.

(1) Integration and compatibility. Mainly according to the combat class deployed at all levels need to have what kind of operational capability, will fight the current class deployment and part of the daily deployment for integration, response to a variety of threats and accomplish a variety of tasks at the same time lay the ships organization foundation.

(2) Ability coordination. Mainly for all levels of operational deployment using the timing and requirements, reasonable personnel and equipment marshalling plan as a whole, maximum limit arouse radar or living resources, make the combat class deployed at all levels is the key can meet the needs of combat operations, and can fulfill the sea service.

(3) Intensive and efficient. It is mainly based on the premise that the minimum personnel required for the maximum combat effectiveness of the single system can be adjusted and changed, so as to achieve solid strength and weak and improve the effectiveness of the deployment organization. 
(4)Fine linkage. Mainly precise refining each class crews at all levels of operations under the deployment of combat operations and daily service responsibilities, specification instruction, password, and command the collaborative relationship, simple implementation order release, remain developers, quickly to complete the task.

\section{Steps of the Ship Deployment Setting and Optimization Adjustment Method}

Deployment setup and optimization adjustment is a comprehensive system project, which should be implemented in the structure, content and function on the basis of sorting out the problems.

Position the Operational Capability of the Paramilitary Units at all Levels. Capability orientation is the top-level design of deployment optimization adjustment, which is the basis for determining the deployment function, framework structure, compatibility method and personnel compilation. So, each model ships should be combined with the mission and the characteristics of this type of ship, further research to determine the type of ship combat deployment ability localization, the ship should have what kind of ability, can perform any task, weapons and equipment and personnel is in what state, definitely need what kind of deployment, to form a scientific and reasonable, to adapt to the operational requirements of the new deployment.

To Determine the Basic Framework for Deployment and to be Compatible with the Original Deployment. When determining the deployment of frame structure, according to the type of ship combat classes at all levels should have the ability and the deployment could perform tasks, systematic analysis of all kinds of combat operations and sea service possible opportunity, what are the key research under combat class deployed at all levels should be action, need what kind of ability, according to the corresponding relation, the deployment of comprehensive compatibility to the old new operational deployment, forming operations class under the deployment of a variety of action. Ensure that the deployment capability structure meets both the operational needs and the performance of the maritime service.

To Determine that the System (equipment) is Used by the Optimal Staffing and Tunable Personnel. Only determines the system (equipment) using the optimal grouping and adjustable personnel, can according to the existing conditions, reasonable deploy fusion, personnel were divided and duties division of refinement. Optimal marshalling means the minimum number of personnel required for the system (equipment) to perform its maximum operational effectiveness under different arrangements of combat operations at all levels. Callable personnel, refers to the deployment of combat classes at all levels, and after completing the preparation of the war, when the more non-optimal marshalling personnel, mainly responsible for the first time to implement the zone to save the damage control. Therefore, the determination of the optimal grouping and adjustable personnel should be quantified for the unit with the fighting positions, according to the different situation of each fighting positions personnel adjustment, determine the scope of the adjustable personnel division battle to save damage control, and responsibility, make reasonable organization, adjustable personnel do its use.

Optimize the Deployment Responsibilities of the Subdivision Personnel. The optimization and refinement of personnel deployment responsibilities is the core content of the deployment optimization adjustment. First of all, it should be based on the job integration and deployment responsibilities, and integrate the responsibilities of the most advanced combat operations such as missile attack, attack and artillery attack. Secondly, the deployment responsibilities are optimized and segmented, and the responsibilities of the personnel after the integration of responsibilities are optimized, improved, and the contents of command authority and cooperative relationship are enriched. Namely: according to "can determine the level to which it was approved by which level of" principle, in the deployment of responsibilities clear command authority in all kinds of combat operations, command, and the corresponding report for instructions, and to dispose of responsibility; Define the cooperative relationship between each position, personnel and other positions and personnel in different actions, as well as the corresponding cooperative password and actions. 
Ships deployment Settings and optimize adjustment, still need to strengthen theoretical research, from the combat mission traction comb naval combat mission list step by step, to clarify the combat class deployment should have the ability of fighting group command the relationship, the scientific definition of command authority at all levels, the elaboration of crews to deploy a fine solution responsibility, really make ships deployed at ordinary times, and the management and training, easy to operation and command in wartime.

\section{References}

[1] Raymond A. Pyles,Robert S. Tripp. A Common Operating Picture for Air Force Materiel Sustainment [R]. www.rand.org. 2008.1-2

[2] Danid Keuhlen,Oliver L.Bryant,Kenneth K.Young. The Common Operational Picture in Joint Vision 2020: A Less Layered Cake[C]. Joint Forces Staff College Joint and Combined Warfare School,2002.

[3] Ahuja G.2000. Collaboration networks,structural holes and innovation: A longitudinal study[J]. Administrative Science Quarterly, 45:425 455.

[4] Dr.David Baar,Garth Shoemaker. Pliable Display Technology for the Common Operational Picture[R]. IDELIX Software Inc.

[5] Peng L, Fang W. Heterogeneity of Inferring Reputation of Cooperative Behaviors for the Prisoners' Dilemma Game [J]. Physica A: Statistical Mechanics and its Applications, 2015, 433: 367-378. 